Slavica

bruxellensia

\section{Slavica bruxellensia}

Revue polyphonique de littérature, culture et histoire

slaves

12 | 2016

Miniatures

\title{
Jan Zatloukal, L'exil de Jan Čep : Un écrivain tchèque en France
}

\section{Barbora Svobodová}

\section{OpenEdition}

\section{Journals}

Édition électronique

URL : http://journals.openedition.org/slavica/1822

DOI : 10.4000/slavica.1822

ISSN : 2034-6395

\section{Éditeur}

Université libre de Bruxelles - ULB

\section{Référence électronique}

Barbora Svobodová, "Jan Zatloukal, L'exil de Jan Čep : Un écrivain tchèque en France », Slavica bruxellensia [En ligne], 12 | 2016, mis en ligne le, consulté le 24 septembre 2020. URL : http:// journals.openedition.org/slavica/1822 ; DOI : https://doi.org/10.4000/slavica.1822

Ce document a été généré automatiquement le 24 septembre 2020.

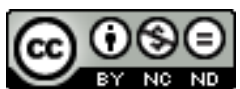

Les contenus de Slavica bruxellensia sont mis à disposition selon les termes de la Licence Creative Commons Attribution - Pas d'Utilisation Commerciale - Pas de Modification 3.0 France. 


\title{
Jan Zatloukal, L'exil de Jan Čep : Un écrivain tchèque en France
}

\author{
Barbora Svobodová
}

\section{RÉFÉRENCE}

Zatloukal, J., L'exil de Jan Čep : Un écrivain tchèque en France, Institut d'études slaves, Paris, 2014,424 p.

1 Jan Čep (1902-1973) est l'un des écrivains tchèques les plus importants du Xx siècle. À maints égards, ce représentant du mouvement catholique a connu le destin typique d'un intellectuel d'Europe centrale de l'époque. Respecté et apprécié au cours des années 1920 et 1930, isolé de son public pendant l'occupation nazie, il a fui la terreur communiste et s'est exilé en France, où il comptait de nombreuses relations personnelles et qu'il considérait, depuis sa jeunesse, comme sa seconde patrie .

2 Ainsi que son titre l'indique, le livre de Jan Zatloukal se focalise plus particulièrement sur cette dernière période de la vie de l'écrivain. Quoique Čep ait vécu presque un tiers de son existence en exil en France, cette étape n'est pas suffisamment documentée par les chercheurs « čepiens » tchèques, de même que ses œuvres et sa personnalité restent presque inconnues en France, non seulement du grand public, mais aussi des historiens de la littérature. L'étude de Zatloukal se fixe donc deux objectifs. D'une part, elle présente la création de Čep en exil, sa vie après qu'il eut quitté la Tchécoslovaquie ainsi que sa personnalité complexe ; d'autre part Zatloukal se concentre sur les problèmes et les circonstances plus générales qui ont influencé le rôle et la réalité quotidienne de l'artiste et intellectuel exilé. Soulignons que ces deux approches sont traitées soigneusement, systématiquement et d'une manière attrayante pour le lecteur.

La première partie de l'ouvrage éclaire le contexte général : elle s'intéresse à des détails biographiques ainsi qu'à la position de Čep dans la société française et ses institutions littéraires. Elle précise également la situation politique et culturelle en Tchécoslovaquie après la Seconde Guerre mondiale. L'auteur compare en outre deux vagues 
d'émigration tchèque - celle de 1948 et celle de 1968 - en soulignant certains liens qui sont difficiles à discerner pour le lecteur français. Il prête une attention particulière à la réception française des livres de Čep ainsi qu'à son activité en exil, notamment ses articles destinés à la presse française, son travail auprès des organisations francotchécoslovaques et de Radio Free Europe, avec laquelle il collabora pendant plus de quinze ans.

4 La deuxième partie analyse l'œuvre littéraire de Čep. Bien qu'il ait rêvé, comme beaucoup d'écrivains exilés, d'écrire un grand roman sur l'histoire de son émigration susceptible de l'introduire dans le monde littéraire français, il composa que six petits récits. Tandis que les autres chercheurs "čepiens" ne considèrent ces textes que comme un chant du cygne, Zatloukal en donne une interprétation fondée sur une lecture minutieuse et détaillée. Après avoir identifié les motifs et thèmes typiques de la poétique " čepienne ", il y trouve aussi des innovations au niveau de la narration et des constructions textuelles. Il se concentre avec la même précision sur deux émissions que Čep prépara pour Radio Free Europe: Comment survivre, une chronique philosophique rebaptisée ensuite Réflexions temporelles et temporelles, et une sorte de "critique parlée " intitulée Le Livre de la semaine. Un chapitre autonome est consacré à Ma sœur l'angoisse, un essai posthume destiné au public français qui, en termes de genre, oscille entre la confession et les mémoires littéraires, philosophiques et spirituels. Enfin l'ouvrage n'évite pas la question du déracinement linguistique et de "la schizophrénie de l'écrivain exilé » qui vit entre deux langues, deux espaces, deux temps et deux publics, ce qui était - malgré son excellente connaissance du français - un trait essentiel pour Čep.

5 Les deux sections sont organiquement liées. Jan Zatloukal fait souvent mention des traits personnels de Čep, donnant ainsi une dimension personnelle aux situations concrètes. Le livre est enrichi de nombreuses annexes rassemblant les récits d'exil de l'écrivain, ses articles pour la presse française, la bibliographie « čepienne » et la liste des textes analysés par l'auteur tchèque dans son émission pour Radio Free Europe.

L'universalité et l'approche détaillée caractérisant la démarche de Jan Zatloukal sont dignes d'intérêt. Sa publication nous permet de voir une image détaillée d'une personnalité exceptionnelle et complexe qui vécut à une époque aux défis multiples.

\section{INDEX}

Index chronologique : XXe siècle, période communiste

Index géographique : Tchécoslovaquie

Mots-clés : Littérature tchèque 